\title{
FACTORES AMBIENTALES QUE AFECTAN LA EDAD AL PRI MER PARTO Y PRIMER I NTERVALO DE PARTOS EN VACAS DEL SISTEMA DOBLE PROPOSITO
}

\section{ENVI RONMENTAL FACTORS THAT AFFECT THE AGE OF FI RST CALVI NG AND CALVI NG I NTERVAL I N COWS UNDER THE DOUBLE-PURPOSE SYSTEM}

Oscar Vergara Gi*, Ph.D, Luz Botero A², Zoot, Caty Martínez B², Bióloga.

${ }^{1}$ Universidad de Córdoba, Facultad de Medicina Veterinaria y Zootecnia, Grupo de Reproducción Animal, Montería Colombia; ${ }^{2}$ Universidad de Sucre, Facultad de Ciencias Agropecuarias, Grupo en Biodiversidad Tropical, Sincelejo Colombia. *Correspondencia: overgara@sinu.unicordoba.edu.co

Recibido: Febrero 19 de 2008; Aceptado: Diciembre 5 de 2008

\section{RESUMEN}

Objetivo. Determinar los factores que influyen en la edad al primer parto (AFC) y primer intervalo de parto (PIDP) en hembras bovinas bajo el sistema de doble propósito, en la finca "El Rodeo", municipio de Magangué, Bolívar - Colombia. Materiales y métodos. Se analizaron 379 datos provenientes de los registros productivos entre los años 1993 hasta 2002, usando el programa estadístico GLM del Statistical Analysis System, donde se obtuvieron la media y el error estándar de cada fuente de variación. En el análisis se consideraron los efectos de año de parto, época de parto, edad al primer parto (no se consideró para EPP), sexo de la cría, grupo racial y peso a los 24 meses. Resultados. La media para la EPP y PIDP fue de $38.9 \pm 3.9$ meses y $469.2 \pm 9$ días, respectivamente, donde el efecto época de parto, fue significativo para la duración del PIDP. Los efectos sexo de la cría, peso a los 24 meses y época, no fueron significativos sobre la EPP. Los efectos año de parto, edad al primer parto, sexo de la cría, peso a los 24 meses no fueron significativos sobre el PIDP. Conclusiones. La EPP y PIDP fueron afectados por el año y la época de parto, respectivamente.

Palabras clave: Bovinos, doble propósito, edad, primer intervalo, partos.

\section{ABSTRACT}

Objective. To determinate the factors that influence the age at first calving (AFC) and first calving interval $(\mathrm{FCl})$ in female cows under the double purpose system on the farm "Rodeo", municipality of Magangué, Bolivar, Colombia. Materials and Methods. Using 379 dates from production records between 1993 and 2002, we applied the GLM program of the Statistical Analysis System (SAS, 2001) to determine the mean and the standard deviation for each 
source of variance. The analysis considered the effects year, season, age at first calving (this was not considered for AFC), gender and weight at 24 months. Results. The mean for $\mathrm{AFC}$ and $\mathrm{FCl}$ were of $38.9 \pm 3.9$ months and $469.2 \pm 9$ days, respectively, and the effect of season of calving had a significant affect on $\mathrm{FCl}$. Gender, weight at 24 months and season were not significant on AFC. Year, age at first calving, gender and weight at 24 months had no significant affect on $\mathrm{FCl}$. Conclusions. The AFC and $\mathrm{FCl}$ were affected by the year of calving and season of calving, respectively.

Key words: Bovines, calving, double purpose, first interval.

\section{NTRODUCCIÓN}

Las características reproductivas determinan la eficiencia reproductiva del hato, y son uno de los aspectos más importantes, ya que tiene impacto en los costos de producción del ganado (1). La eficiencia reproductiva determina en gran medida la rentabilidad de una empresa ganadera, pues ésta depende del período de reproducción de las hembras. Sin embargo, las características relacionadas con la eficiencia reproductiva han sido poco incluidas en programas de mejoramiento animal por tener bajos grados de herencia $(2,3)$ y por considerarlas como componentes de manejo del sistema de producción específico.

Los bajos índices productivos son el reflejo de las bajas eficiencias reproductivas, que son las principales limitantes en los sistemas de producción ganadera de doble propósito del Caribe colombiano, siendo el intervalo de parto (IDP) uno de los parámetros que más afecta el desempeño reproductivo de las hembras bovinas. Los intervalos de parto prolongados son consecuencia de la interacción de los múltiples factores, entre ellos están: la edad al primer parto (EPP), grupo racial, nutrición, peso al servicio, año y época de parto (condiciones ambientales) y condiciones sanitarias, entre otras (4-6). En la región Caribe, los hatos vacunos manejados en el sistema de doble propósito presentan un IDP alrededor de 15 - 16 meses (450 - 480 días), el cual sigue siendo indicativo de baja eficiencia reproductiva, ya que se considera ideal para este sistema un IDP de 365 días para poder obtener parámetros productivos y reproductivos económicamente competitivos $(7,8)$. Pero dadas las condiciones del trópico, de manejo y nutrición se puede considerar óptimo un IDP de 13 - 14 meses $(7,8)$.

La edad al primer parto (EPP) está relacionada con la edad en que se produce el primer servicio de las novillas y depende principalmente del manejo y la alimentación que se le proporciona durante el período de crecimiento. A pesar de no constituir una medida de fertilidad, Ia EPP afecta significativamente la eficiencia productiva (9). Navarrete et al (10), en el departamento de Córdoba en 29 fincas del sistema vacuno doble propósito, encontraron una edad al primer parto de 38.6, 39.4 y 41.1 meses durante los años de 1991, 1992 y 1993 respectivamente, cifras que están por encima de los parámetros que podrían considerarse como aceptables para el sistema de producción y para las condiciones de la zona que se considera su ideal una EPP alrededor de 30 - 34 meses. Marulanda (11), reportó que lo ideal es que la edad al primer parto coincida cuando la novilla está lo suficientemente madura para soportar el estrés lactacional.

Según Botero (12), en la medida en que se ponga a producir más temprano una hembra, mayor es el número de terneros y leche producida por año de vida y la productividad es mayor en el hato. I gualmente, Rodríguez et al (6) encontraron que la obtención del primer parto a una edad temprana ofrece ventajas como un año más de vida reproductiva.

El objetivo del presente estudio fue conocer los factores que influyen sobre el PIDP y EPP en bovinos manejados bajo el sistema doble propósito. 


\section{MATERI ALES Y MÉTODOS}

Sitio de estudio. El presente trabajo se realizó en la hacienda "El Rodeo", Iocalizada en el municipio de Magangué, Bolívar, ubicada entre los $8^{\circ} 23^{\prime}$ de latitud norte y $74^{\circ} 42^{\prime}$ de longitud occidental del meridiano de Greenwich, a una altura de 27 m.s.n.m, con temperatura promedio anual de $28^{\circ} \mathrm{C}$, humedad relativa del $75 \%$, precipitación media anual de $1334 \mathrm{~mm}$ y pertenece a la formación climática de bosque seco tropical (13).

Caracteristicas de la finca. El Rodeo posee una extensión de 500 hectáreas, de las cuales 350 presentan una topografía ligeramente ondulada, bien drenada, con suelos de textura arcillosa y de fertilidad moderada. Los pastos predominantes son: Botriochloa pertusa (Kikuyo o colosuana), Dichanthium aristatum (Angleton) y Dichanthium anulatum (Climacuna); en las partes inundables se pueden encontrar Brachiaria radicans (Pará o Braquipará), Echinochloa polystachya (Pasto alemán) y Athephora hermaphrodita (Canutillo). Asímismo, se encuentran sectores con árboles de Pithecelobium saman (Campano), Calliandria pitieri (Carbonero), Guazuma ulmifolia (Guásimo), Spondias mombim (Hobo), Enterolobium cyclocarpum (Orejero) y Crescentia cujete (Totumo). Las otras 150 hectáreas tienen establecidos bancos de árboles maderables, como son: Eucalyptus camaldulensis (Eucalipto), Bombacopsis quinata (Tolua o Ceiba Roja), Tectona grandis (Teca) y Gmelina arborea (Melina), las cuales se encuentran en asocio con arbóreas como potencial forrajero, entre las que se encuentran Leucaena leucocephala (Leucaena) y el Gliricidia sepium (Matarratón); estas áreas se encuentran habilitadas para el pastoreo de terneros lactantes y destetos.

Caracteristicas del sistema. El sistema de producción ganadero es doble propósito extensivo tradicional, cuya principal actividad es la producción de leche, cría del ternero (a) y levante de las novillas de reemplazo. A estos animales se les suministró todo el tiempo sal mineralizada al $8 \%$ a voluntad. En las épocas de escasez de alimento se suministró heno, ensilaje, semillas de algodón con gallinaza, urea y melaza, como suplementación a los animales adultos, mientras que los terneros fueron suplementados con suero dulce, melaza y ensilaje. La base genética del hato está constituida por animales mestizos resultante de los cruces Cebú Colombiano x Pardo, Cebú Colombiano x Criollo, Cebú Colombiano $x$ Holstein, Cebú Colombiano x Simental, Pardo $x$ Sahiwal y viceversa. Por otra parte, se manejó rotación de potreros sin tener en cuenta el tiempo de ocupación y descanso del potrero, sino la disponibilidad de alimento (forraje). La reproducción se realizó mediante monta natural, utilizando toros con mayor porcentaje de cebú para los lotes de novillas con mayor porcentaje europeo y toros con mayor porcentaje de europeo para los lotes de novillas con mayor porcentaje de cebú. Estas novillas se incorporan a su actividad reproductiva a partir de los dos años de edad, sin tener en cuenta su peso en ese momento.

Para la realización del presente estudio retrospectivo se analizaron 379 datos de la edad al primer parto y primer intervalo de parto, tomados entre los años 1993 y 2002 de los registros productivos llevados en la Finca. Los registros productivos fueron analizados por el método de los cuadrados mínimos de Harvey, utilizando el paquete estadístico General de Modelos Lineales (GLM) de Statistical Analysis System (14) versión 8.0, donde se tuvieron en cuenta los efectos fijos año y época de parto, sexo de la cría, peso al servicio y la edad al primer parto.

El análisis se basó en el siguiente modelo estadístico lineal:

$$
Y_{i j k l m n}=\mu+A_{i}+E_{j}+M_{k}+S_{l}+P_{m}+e_{i j k l m n}
$$

Donde:

$Y_{\mathrm{ijklmno}}=$ EPP o PIDP

$=$ media general de la EPP o PIDP

$A_{i}=$ Efecto fijo del i-enésimo año de parto de la vaca, variando i de 1 a 10, siendo: 1: (1993); 2: (1994); 3: (1995); 4: (1996); 5: (1997); 6: (1998); 7: (1999); 8: (2000); 9: (2001); 10: (2002). 
$\mathrm{E}_{\mathrm{j}}=$ efecto fijo del i-enésima edad al primer parto, variando j de 1 a 5, siendo:

1: 29 - 32 meses de edad; 2: 33 - 36 meses de edad; 3: 37 - 40 meses de edad; 4: 41 44 meses de edad; 5: más de 45 meses de edad (considerado para el modelo de PIDP). $M_{k}=$ Efecto $k$-enésima época del año en que sucede el parto de la vaca, variando $k$ de 1 a 4, siendo: 1: enero - marzo; 2: abril - junio; 3 julio - septiembre; 4: octubre diciembre.

$\mathrm{S}_{\mathrm{l}}=$ Efecto fijo $\mathrm{m}$-enésimo sexo del ternero de la vaca, variando de 1 a 2 , siendo:

1: machos y 2: hembras

$P_{m}=$ Efecto fijo n-enésimo peso de la novilla a los 24 meses de edad, variando $\mathrm{n}$ de $1 \mathrm{a}$ 6, siendo: 1: peso de $210 \mathrm{~kg}-229 \mathrm{~kg}$; 2: peso de $230 \mathrm{~kg}$ - $249 \mathrm{~kg}$; 3: peso de $250 \mathrm{~kg}$ - $269 \mathrm{~kg}$; 4: peso de $270 \mathrm{~kg}$ - $289 \mathrm{~kg}$; 5: peso de $290 \mathrm{~kg}$ - $309 \mathrm{~kg}$; 6: más de $310 \mathrm{~kg}$ $\mathrm{e}_{\mathrm{ijklmn}}=$ error experimental.

\section{RESULTADOS}

Las medias para EPP y PIDP fueron de $38.9 \pm 3.9$ meses y $469.2 \pm 9$ días con un coeficiente de variación del 10 y 17.3 $\%$, respectivamente. En la tabla 1 se muestran el análisis de varianza para EPP y PIDP en vacas mestizas manejadas bajo el sistema de doble propósito. Para la EPP no se encontró efecto significativo

Tabla 1. Análisis de varianza para la EPP y el PIDP en vacas mestizas.

\begin{tabular}{ccccccc}
\hline \multicolumn{3}{c}{ EPP } & \multicolumn{4}{c}{ PIDP } \\
\hline Fv & Gl & $\begin{array}{c}\text { Cuadrados } \\
\text { medios }\end{array}$ & Pr > F & Gl & $\begin{array}{c}\text { Cuadrados } \\
\text { medios }\end{array}$ & Pr > F \\
\hline $\begin{array}{c}\text { Peso 24 } \\
\text { meses }\end{array}$ & 5 & 29.824 & 0.0828 & 5 & 3.390 .465 & 0.7637 \\
Epp & & & & 4 & 9.527 .330 & 0.2165 \\
Sexo & 1 & 0.326 & 0.8835 & 1 & 5.952 .159 & 0.3415 \\
Año & 9 & 61.363 & 0.0001 & 9 & 10.024 .454 & 0.1365 \\
Epoca & 3 & 15.940 & 0.3699 & 3 & 25.090 .866 & 0.0102 \\
Error & 358 & 15.162 & & 354 & 6.562 .040 & \\
\hline
\end{tabular}

$(p>0.05)$ del peso, sexo y época de parto, pero si hubo efecto significativo $(p<0.05)$ del año de parto. Para el PIDP se encontró efecto significativo $(p<0.05)$ de la época de parto, no encontrándose efecto significativo $(p>0.05)$ del peso, EPP, sexo y año de parto.

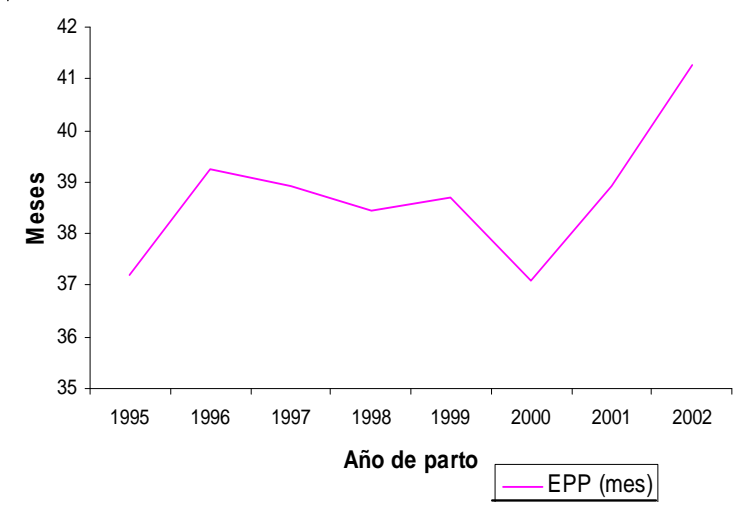

Figura 1. Tendencia de EPP en los años de estudio en hembras mestizas
En la figura 1 se presenta la tendencia de la EPP en los diferentes años de estudio. La figura 2 muestra la tendencia del PIDP en las diferentes épocas.

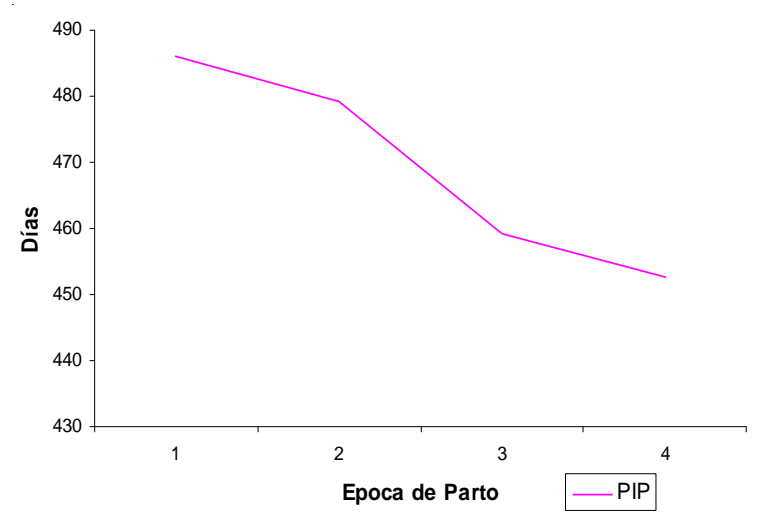

Figura 2. Tendencia de PIDP en las diferentes épocas de estudio en hembras mestizas 


\section{DISCUSIÓN}

La media de EPP está acorde con los valores encontrados por varios autores en ganado doble propósito y cruzado $(10,15-17)$ y es superior a la reportada en ganado cruzado Holstein por Cebú, Holstein por Gyr y Nelore (18-20). Esta media se puede considerar adecuada bajo las condiciones del trópico bajo colombiano y por el manejo alimenticio y reproductivo que se les da a los animales en la etapa de cría y levante. Aunque Notter (21) considera que la EPP en los países tropicales ocurre tardíamente y la mayoría de las veces es atrasada por los productores y por el bajo nivel nutricional de los animales. Respecto al PIDP, se han reportado valores superiores al encontrado en este estudio en ganado doble propósito y Cebú $(22,23)$. Un valor igualmente superior fue reportado por Schellenberg y Weniger (24), en un estudio realizado en los departamentos de Córdoba y Sucre, donde el PIDP fue de 513 días. Un valor inferior a este estudio fue reportado en una población doble propósito (25).

Considerando que las vacas de primer parto tienden a presentar un IDP más prolongado por las condiciones fisiológicas inhibitorias de la actividad ovárica al establecerse una competencia entre crecimiento, reproducción y producción láctea, se considera aceptable un PIDP de 469.2 días para la zona donde se realizó el estudio; además del método de ordeño con la cría, alarga un poco el PIDP.

Al igual que en este estudio otros autores han encontrado diferencia significativa $(p<0.05)$ del año de parto sobre la EPP (17$19,26,27)$. A diferencia de este estudio se encontró diferencia no significativa del año de parto en ganado Nelore (28). Teniendo en cuenta que la alimentación del sistema de producción se basa en pasturas y las variaciones climáticas en los años de estudio, evidenció que la EPP depende de las condiciones nutricionales a las cuales está sometido el rebaño. Según Notter (21) en países tropicales los niveles nutricionales bajos son determinantes en un mejor desempeño reproductivo de los animales.

El efecto no significativo de la época de parto sobre la EPP contrasta con lo encontrado en ganado Holstein por Cebú, Holstein por Gyr y cruzado $(18,19,27)$. Al igual que este estudio el sexo de la cría no tuvo efecto significativo sobre la EPP en ganado cruzado, Romosinuano y Chianina $(27,29,30)$.

Con relación a los factores que afectan el PIDP, los resultados encontrados concuerdan con los reportados por Araujo (31), al no encontrar diferencia significativa en los pesos corporales sobre el IDP. Esto indica, que no es necesario esperar a que las novillas alcancen un peso elevado para ser servidas, ya que esto no va a incidir sobre el PIDP.

El efecto no significativo de la EPP sobre el PIDP coincide con lo reportado con Colina et al (32). Caso contrario fue reportado por Wolf et al (33) quienes encontraron un efecto altamente significativo $(p<0.01)$ de la EPP sobre el IDP. El efecto no significativo $(p>0.05)$ del sexo de la cría sobre el PIDP está de acuerdo con lo reportado por otros autores en hembras cruzadas $(27,34,35)$.

El efecto no significativo $(p>0.05)$ del año de parto sobre el PIDP concuerdan con los hallados por Casares y Retamoza (36) y Martínez (37). A diferencia de los autores anteriores se encontró diferencia significativa $(p<0.05)$ del año del parto sobre el primer intervalo de parto en bovinos cruzados y Chianina $(27,30)$.

El efecto significativo $(p<0.05)$ de la época de parto sobre el PIDP concuerda con los reportados por varios autores $(25,30,37)$. Caso contrario, encontraron Casares y Retamoza (36) y Martínez (38). En la figura 2 se muestran las variaciones del PIDP según la época del año en que ocurre el parto, evidenciándose que el PIDP fue más amplio en la época 1, que va desde el mes de enero a marzo, coincidiendo así con la época del año en la cual las precipitaciones son menores, así mismo, el PIDP más corto se presentó en la época 4, que va desde el mes de octubre a diciembre, la cual coincide con la época donde ocurren las mayores precipitaciones (mes de octubre). Aunque se esperaba que no hubiese diferencias significativas entre las épocas con relación al PIDP, por el plan de suplementación dado 
a los animales durante la época de escasez de alimento (enero a marzo), la diferencia estadística puede ser atribuida a ciertas variaciones que se dan en los alimentos en las diferentes épocas, capaz de influir en el PIDP y otras prácticas de manejo, sanitarias o reproductivas (30).

En conclusión, se puede afirmar que la edad al primer parto y el primer intervalo de parto fueron afectados por el año y la época del parto bajo las condiciones del presente estudio.

\section{Agradecimientos.}

A los propietarios de la hacienda "El Rodeo" y a los zootecnistas Carlos Medina Galindo y José Pestana Soto.

\section{REFERENCI AS}

1. Casas E, Tewolde A. Evaluación de características relacionadas con la eficiencia reproductiva de genotipos criollos de carne en el trópico húmedo. Arch Latinoam Prod Anim 2001; 9(2): 68-73.

2. Duarte A, Thorpe W, Tewolde A. Reproductive performance of purebred and crossbred beef cattle in the tropics of Mexico. Anim Prod 1988; 47: 11-20.

3. Gregory KE, Bennett GL, Van Vleck LD, Echterncamp SE, Cundiff LV. Genetic and environmental parameters for ovulation rate, twinning rate, and weight traits in a cattle population selected for twinning. J Anim Sci 1997; 75: 1213-1222.

4. Domínguez C, Herrera P, Birbe B, Martínez N. Impacto de la suplementación estratégica con Bloques nutricionales en vacas de doble propósito En: Mejora de la ganadería mestiza doble propósito, Ed.Maracaibo, Venezuela: Asto Data S.A; 1998.

5. Verde Omar. Estimación del valor genético para reproductores bovinos doble propósito. En: Mejora de la ganadería mestiza doble propósito. Ed. Maracaibo, Venezuela: Astro Data S.A; 1998.

6. Rodríguez VA, Omar V, Berbin W, Rodríguez M. El gen y formación del ganado tipo Yaracal. Comportamiento productivo y reproductivo. En: Mejora de la ganadería mestiza doble propósito. Ed. Maracaibo, Venezuela: Asto Data. SA; 1998.
7. Guzmán PS. Situación actual del sistema de ganadería bovina doble propósito en Colombia. En: Memorias "Ganadería de doble propósito". ICA. 1995.

8. Villar Jaime. Índice reproductivo en Ganado de doble propósito. En: Memorias "Ganadería de doble propósito”. ICA. 1995.

9. Hernández G, Alvarado L. Características reproductivas y productivas de F1 Holstein Cebú y Holstein Criollo en el trópico colombiano. En: Memorias "Ganadería de doble propósito". ICA. 1995.

10. Navarrete M, Abuabara $Y$, Mendoza G, Martínez G, Corredor G, Serrano G, Dueñas G. Evaluación de la reproducción en la ganadería de doble propósito en Córdoba. En: La investigación pecuaria. Santafé de Bogotá D.C: CORPOICA; 1998.

11. Marulanda E. Evaluación de la edad del servicio y su incidencia en la productividad y reproductividad de las novillas Cebú. Revista El Cebú ASOCEBú 1996; 43:44-64.

12. Botero L. Criterio para entrar novillas a toro. En: II Seminario de producción agropecuaria Mompox 1990.

13. Holdrige LR. Life zone ecology. San J osé de Costa Rica: Trop, Sci. Cient; 1987. 
14. SAS/STAT- User's Guide (Relase 8.0), Cary, NC, USA: SAS inst. Inc; 2001.

15. Pérez A, Khalil R, Vaccaro L, Rodríguez MI. Edad al primer parto y su relación con la producción lechera en vacas de doble propósito. Arch Latinoam Prod Anim 1997; 5(Supl. 1): 518-520.

16. Botero R. Análisis productivo y reproductivo del ganado bovino de doble propósito de cinco Centros de Servicios Tecnológicos de FEDEGAN Colombia. Tesis Ciencia y Producción Agropecuaria. Honduras: Universidad Zamorano; 2005.

17. García G, Maldonado-Estrada J, López J. Caracterización productiva y reproductiva de las explotaciones ganaderas del bajo cauca y el litoral atlántico antioqueños. II. Comportamiento de cuatro grupos raciales Bos indicus en un sistema de bosque seco tropical (bs-T). Rev Col Cienc Pec 2003; 16(2): 117-125.

18. Grossi S, Freitas M. Eficiência Reprodutiva e Produtiva em Rebanhos Leiteiros Comerciais Monitorados por Sistema Informatizado. Rev Bras Zootec 2002; 31 (Supl 3): 1362-1366.

19. Facó O, Lôbo R, Martins R, Lima F. I dade ao primeiro parto e intervalo de partos de cinco grupos genéticos Holandês $x$ Gir no Brasil. Rev Bras Zootec 2005; 34(6): 1920-1926.

20. Gunski R, Garnero A, Becerra L, Corrado, M, Lobo R. Idade ao primeiro parto, período de gestação e peso ao nascimento na raça Nelore. Ciencia Agronomica 2001; 32(1): 46-42

21. Notter DR. Maximizing fertility in animal breeding programs. Blacksburg: Virginia Polytechnic Institute State University, Department of Animal and Poultry Sciences, 1995. p. in reg. (XI Congresso Brasileiro de Reprodução Animal. Belo Horizonte; 1995.
22. Ossa G, Perez J, Alvarado L, Oyola E, Guerrero M, Garcia A, Torregroza L, Morelos J, Chica E. Evaluación genética del comportamiento productivo y reproductivo de bovinos en sistemas de producción del trópico bajo. [fecha de acceso 27 de diciembre del 2007]. URL disponible en: http: / / www.turipana.org.co/ genetica.htm

23. Rodríguez E Olaya R. Eficiencia reproductiva de ganado cebú registrado en Colombia. Revista El Cebú 1982; 204: 16-24.

24. Schellenber R Weniger J Sistemas de producción de leche y carne en fincas ganaderas de la Costa Atlántica de Colombia. Informe Técnico № 5 GTZ. 1985

25. Hernández Reyes E Segura Correa V Segura Correa J Osorio Arce M. Intervalo entre partos, duración de la lactancia y producción de leche en un hato de doble propósito en Yucatán, México. Agrociencia 2001; 35: 699-705.

26. Valle A. Comportamiento reproductivo de vacas mestizas en cinco fincas de la región de Carora, Estado Lara. Venezuela. Zoot Trop 1985; 3(1) : 3-28.

27. Perotto D, Miyagi AP, Souza JC, Moletta JL, Freitas JA. Estudos de características reprodutivas de animais da raça Canchim criados a pasto, no estado do Paraná Brasil. Archi Vet Sci 2006; 11(2):1-6.

28. Da Silveira J, McManus C, Mascioli A, Da Silva L, Da Silveira A, Garcia J, Louvandini $\mathrm{H}$. Fatores ambientais e parâmetros genéticos para características produtivas e reprodutivas em um rebanho Nelore no Estado do Mato Grosso do Sul. Rev Bras Zootec 2004; 33(6) : 1432-1444.

29. Suárez M, Ossa G, Pérez J. Factores ambientales y genéticos que influyen sobre la edad al primer parto en hembras de la raza Romosinuano. Rev MVZ Córdoba 2006; 11(1): 738-743. 
30. Azevêdo D Martins R Bozzi R Forabosco $F$ Mendes $C$. Parâmetros genéticos e fenotípicos do desempenho reprodutivo de fêmeas Chianina. Ver Bras Zootec 2006 35(3): 982-987.

31. Araujo - Febres O. Experiencia con bovinos mestizos en la Hacienda la Esperanza (Luz) en Perijá. Rev Fac Agron 19952007 12: 121-131.

32. Colina J, Verde O, Martín H, Barrios D. Eficiencia reproductiva de un rebaño Holstein puro bajo condiciones tropicales. Rev Fac Cienc Vet 2000;41(1): 33-40.

33. Wollff M Monardes H Ribas N. Fatores ambientais sobre a idade ao primeiro parto, dias abertos e intervalo entre partos em vacas da raça holandesa na bacia leiteira de castrolanda, estado do Paraná. Archi Vet Sci 2004 9(2): 35-41.

34. Alencar M Bugner M. Desempenho reprodutivo de fêmeas das raças Canchim e Nelore. IV. Segundo parto. Pesq Agrop Bras 1989; 24(10): 1217-1220.
35. Pádua J Munari D Watanabe Y Verde C Leite J Mello M. Avaliação de efeitos de ambiente e da repetibilidade de características reprodutivas em bovinos da raça Nelore. Rev Bras Zootec 1994; 23(1): 126-132.

36. Casares L Retamoza E. Evaluación de la eficiencia reproductiva en ganado bovino del sistema doble propósito en condiciones de semiestabulación en la Granja Santiago del municipio de Santiago de Tolú, Sucre. [Trabajo de Grado Zootecnia]. Sincelejo, Colombia: Facultad de Ciencias Agropecuarias. Universidad de Sucre; 2003.

37. López J Vaccaro L. Comportamiento productivo de cruces Holstein Friesiancebú comparados con Pardo Suizo-cebú en sistemas de doble propósito en tres zonas de Venezuela. Zootec Trop 2003; 20(3):397-414.

38. Martínez G. Edad al primer parto e intervalo entre parto en ganado pardo suizo criado en el Trópico subhúmedo. México D.F. 2000. [Fecha de acceso 22 de diciembre del 2007]. URL disponible en: http:// ecologia.uat. $\mathrm{mx} /$ biotam/v4n2/art3.html 